\title{
Network social capital as an outcome of social movement mobilization: Using the position generator as an indicator of social network diversity
}

\author{
D.B. Tindall ${ }^{\mathrm{a}, *}$, Jeffrey Cormier $^{\mathrm{b}}$, Mario Diani $^{\mathrm{c}}$ \\ a Department of Forest Resources Management, Department of Sociology, University of British Columbia, 6303 N.W. Marine Drive, Vancouver, B.C., Canada V6T 1Z1 \\ ${ }^{\mathrm{b}}$ Formerly of King's College, University of Western Ontario, Canada \\ c ICREA-Universitat Pompeu Fabra, Barcelona, Spain
}

\section{A R T I C L E I N F O}

\section{Keywords:}

Network diversity

Outcomes of social movements

Environmental movement

Social capital

Position generator

Environmental activism

\begin{abstract}
A B S T R A C T
In the social mobility literature, the position generator (PG) has been used to examine the relationship between the structural location of individuals, and outcomes such as obtaining a high status job. Diversity of occupational ties (as measured by the PG) is also a significant predictor of an individual's cultural capital. A great deal of work has also been done in the field of social movements examining the relationship between networks and mobilization. However, only limited attention has been given to the position generator in this literature. Also, while past research has demonstrated that prior network ties to activists is one of the most important predictors of current activism, relatively little research has been devoted to examining network structure as an outcome of activism. The present paper builds upon these insights by utilizing data collected with the position generator on a sample of environmental movement members, and examining the relationship between individual activism (as an independent variable) and diversity of occupational ties (as a dependent variable). The result of key theoretical significance is that those who are more active in the environmental movement develop a greater diversity of occupational ties to other environmentalists. Results suggest that this process occurs over time. These findings provide evidence that social capital (as indicated by network diversity) is one outcome of social movement mobilization.
\end{abstract}

(C) 2012 Elsevier B.V. All rights reserved.

\section{Introduction}

Several years of analysis on the outcomes of social movements now permit a largely affirmative response to the question: "Do social movements matter?" However, a supplementary question, namely, "How do social movements matter?" requires still greater theoretical and empirical elaboration. We know that movements matter in a variety of intended and unintended ways. While there are many difficulties to what may be called "outcome studies" (see Giugni, 1999), it is now commonly understood that movements can have at least three major types of change impact: political, biographical and cultural. The exploratory research presented here is an effort to extend the theoretical and empirical boundaries

\footnotetext{
放 This research was supported by a Standard Research Grant from the Social Sciences and Humanities Research Council of Canada (\#410-2005-1118). An earlier version of this manuscript was presented at the Annual Meetings of the American Sociological Association, in New York, in August 2007. We would like to thank the following people for their contributions to this research: Bonnie Erickson, Barry Wellman, Robert Brym, John Hannigan, Nan Lin, Sean Lauer, Beth Michaela Simpson, Todd Malinick, Mark Stoddart, Andrea Streilein, and Joanna Robinson. We dedicate this article to Julie Michaud.

* Corresponding author. Tel.: +1 604822 2363; fax: +1 6048226161.

E-mail address: tindall@mail.ubc.ca (D.B. Tindall).
}

of possible social movement outcomes. In other words, we wish to add to the political and policy successes of a movement, the biographical impacts movements have on individuals, and the large-scale cultural and values shifts that result from social movement activity, a fourth category of outcomes: social capital outcomes (Diani, 1997). More specifically, we examine the relationship between individual activism, and ties to environmental organization members from diverse occupational backgrounds. The latter measure, network diversity, has been identified as a significant form of social capital (Erickson, 2003).

We conduct an analysis of previously collected survey data obtained from members of three formal environmental organizations that make up part of the Wilderness Preservation movement in British Columbia, Canada. Using the position-generator technique developed by Lin et al. (2001b), we examine the relationship between level of social movement activism and the diversity of the occupational ties that respondents have to other environmental organization members. We argue that having a greater number of ties to a diversity of others produces social capital benefits for the individual movement member, and potentially for the movement more generally.

The analysis proceeds in the following manner. First we review the literature on the three common categories of social movement outcomes that have emerged to date. This is followed by 
a discussion of a possible fourth category, namely social capital benefits that result from movement activism. We outline a series of six expectations about the relationship between activism and the production of social capital outcomes. We then describe our measures, focusing on a description of the position-generator. We present our results, compare them with a supplementary study, and conclude with a discussion of the individual, organizational and community level social benefits to social movement activity.

\section{Broadening movement impacts}

Three distinct trends emerge from current work on the impact of social movements. Broadly speaking, researchers have focused either on the individual-level biographical impacts of participating in movement activity (McAdam, 1989), the changes and shifts in large-scale society-wide cultural values (Rochon, 1998), or the changes that take place politically, usually in terms of public policy (cf., Giugni et al., 1999; Meyer, 1999). Granted, this neat tripartite division belies a much more nuanced and messy empirical reality. Untangling the causal threads between movement actions and outcomes is not easy, and arguably poses the greatest challenge to research into movement outcomes (Giugni, 1999; Diani, 1997). Yet outlining these research foci as if they composed discrete outcomes brings into relief those areas that deserve greater attention.

The first two areas - the impact on individuals and the impact on cultural values - have received significantly less attention than have political orientated outcomes (Giugni, 1999). McAdam (1989) has been forefront in looking at the biographical effects that participation has on individuals. He shows that participation in the Civil Rights movement (McAdam, 1988) and the New Left movement (McAdam, 1999) had enormous impacts at both the individual and aggregate level. A second set of outcomes is related to the ways social movements impact broad cultural values. Rochon (1998) argues that new cultural values enter public debate through first the formation of what he calls "critical communities": groups of thinkers, intellectuals, etc., who develop innovative ways of looking at otherwise familiar issues. Rochon maintains that cultural changes happen when movements latch onto and succeed in diffusing the ideas of a critical community. Cultural change includes both a change in mentalities as well as a change in public policy (Rochon, 1998:9).

Much more attention has been devoted to what are commonly grouped as political impacts (Giugni, 1999). While political outcomes are in most instances broadly defined (c.f., Andrews, 1997, 2004) they usually include either some kind of push for or later implementation of public policy (Burstein, 1999). These studies attempt to connect some element or combination of elements of the movement - organizational structure, framing of issues, and political opportunities - with a specific legislative or policy outcome (McCammon et al., 2001; Soule and Olzak, 2004; Amenta et al., 1992).

There are two fundamental critiques of impact studies. The most often expressed which encompasses individual biographical, cultural or political change is the difficulty in drawing a direct causal link between the movement's actions and a particular outcome (Andrews, 2004; Giugni, 1999; Diani, 1997). It is possible, that the individual, cultural or political change is the result of some other cause - in which case we have a spurious relationship - or would have happened anyway, despite the actions of the movement. This latter counterfactual is difficult to establish because the mere fact we are looking at a movement impact means the movement has already been present. (But historical and/or cross-cultural comparisons of similar cases can sometimes be helpful.) Second, movement and organizational goals are never homogeneous. Well understood is the fact that organizations tend to spend an inordinate amount of time and effort discussing what the movement's goals are. Complicating matters still is the fact that movement goals often change over time.

Faced with this chaos and complexity researchers have usually tended towards reductionism: freeze the movement's goals at one particular time while reading goals back from a clearly stated policy achievement. Such simplification eliminates some of the distracting background created by the multifarious activities of the movement, thereby allowing researchers to focus on what they take as the direct link between movement action and impact. While initially attractive because of its apparent parsimony, this strategy distracts from greater exploration into the diversity of influences and impacts that social movements contribute to social life.

Another strategy, the one that we pursue here, is to broaden the relationship between movement and movement activity and outcomes (Andrews, 2004; Diani, 1997), by including among possible outcomes what we call "social benefits" of movement activity.

\section{Social capital outcomes as a social benefit}

The present study is rooted in a research tradition that treats social network ties as an "independent variable" that produces activism (the dependent variable). A number of scholars have examined the effect of networks on activism (e.g., McAdam, 1986; Gould, 1993; Diani, 1995; Kitts, 1999; Tindall, 2002; Diani and McAdam, 2003). A variety of arguments have been made about the effect of network ties on individual activism. It is generally argued that the greater the number of ties one has, the more active $\mathrm{s} /$ he will be. A subset of the processes involved include increased communication and diffusion of information, social influence, and social support. While linked to this approach, our study intentionally sets out to distinguish itself from this tradition. In the present research, in order to fully explore the social consequences of social movement activity, we argue that it might be useful to consider a reverse causal logic between social networks and movement mobilization, and treat social networks and network ties as outcomes of movement mobilization, rather than as solely as facilitators of the latter (c.f., McAdam, 2003). Diani (1997) in particular points to four such possible social network consequences for movements and movement organizations: increased mobilization capacity for future action, the development of subcultures and countercultures, increased personal networks with those outside the movement, and the production, dissemination and diffusion of novel ideas. In short, Diani suggests we view "networks as a product as well as a precondition of action" thereby expanding the range of possible movement outcomes (Diani, 1997:143).

Recent research on networks and social capital (Lin et al., 2001a; Lin and Erickson, 2008) and networks and social movements (Diani and McAdam, 2003) help orient our present analysis. Key is the notion that social capital is generated by and through social networks (Bourdieu, 1986; Coleman, 1988; Lin, 2001b; Lin et al., 2001a). Individuals' social ties to one another allow for the exchange of valuable social resources. Four such assets can be discerned (c.f., Lin, 2001b). First, movement information often flows between individuals who have regular contact with each other within the context of activism (Oliver and Myers, 2003). Power and political influence can be obtained by having key social ties to agents such as movement leaders or political elites (Diani, 2003). Legitimacy and certification of the movement organization as a whole or individual activist may come through network ties. Finally, social capital resources such as sense of identity, solidarity and emotional support help activists through the often exhausting demands of social activism (Passy, 2003). 


\section{Networks, social capital, and the position generator}

Our argument in this paper is that network diversity serves as a form of social capital, and that one's level of activism is positively associated with network diversity. In other words, the more active you are, the more ties you make to other people from diverse occupational backgrounds within your environmental organization.

In the present analysis we do not set out to empirically examine whether network diversity serves as a form of social capital, rather we focus on explaining network diversity as an outcome. Nevertheless, there is some evidence in the literature regarding the former issue.

The most prominent argument about this is Nan Lin's “extensityof-ties proposition" (Lin, 1999). Lin uses the term "extensity" to refer to network diversity. His proposition states: "the more extensive the networks, the better the social resources to be accessed and mobilized" (Lin, 1999:483).

A variety of empirical studies have examined the correlates of personal network diversity (for an overview of some of these see Lin and Erickson, 2008). For example, Erickson (1996) found that people with more diverse networks (in terms of ties to people from different occupations) had greater cultural capital. Harshaw and Tindall (2005) found that people with more diverse ties (to occupations) had greater identity diversity, and indirectly, more diverse values.

More generally, Erickson (2003) has elaborated the payoff of network diversity. She elegantly states:

Variety is the key. Knowing many kinds of people in many social contexts improves one's chances of getting a good job, developing a range of cultural interests, feeling in control of one's life and being healthy. Sometimes knowing many kinds of people is helpful because it improves the chances of having the right contact for some purpose: hearing of an attractive job opening, borrowing a lawnmower, getting the home cleaned.

Network variety can also be useful in itself, for example in jobs that call for diverse contacts. Either way, the critical matter is the variety of acquaintances and not the mere number. (Erickson, 2003:25)

\section{Hypotheses}

A starting point for our theoretical argument is the claim that social movement activities serve as a type of "foci" (Feld, 1981). Foci are organizations or events that coordinate social interaction in place and time. They can be small or large, serving as organizing structures for only a few people (as in a family), or for many people (as in a large corporation). Foci also vary in the degree of constraint and level of commitment they demand of participants. While social network ties may be formed through random interaction among individuals, ties are more likely to form where individuals have a shared orientation to one of these foci. In other words, A and B are more likely to belong to the same social network if they go to the same school or belong to the same club than if they do not have a shared foci. For environmentalists, important foci may include environmental group meetings and protests. These are sites where individuals can form and strengthen social network relations with people who have similar interests (see Tindall et al., 2009 as well as, on peace activists, Diani, 2009). An "unintended" by-product of activism (or participation in social movement events), we argue, is exposure to people from a wider variety of backgrounds (e.g., in terms of occupations) and thus development of a more diverse personal network (and thus a higher level of personal network social capital).

The research strategy developed here derives from these observations about the production of social capital through networks.
More specifically, we are interested in how the production of social capital relates to the possible social benefits that accrue from social movements, as an outcome of social movement activity. Our overarching research question reflects this concern: What is the relationship between level of movement participation, length of time of that participation, and the generation of social capital as embedded in the diversity of one's network ties? We would expect to see that longer more intense participation in a movement would lead to increased production of social capital. Several hypotheses guide our analysis of social capital outcomes. First, we expect that:

H1a. Level of activism will be positively associated with diversity of occupational ties to other environmentalists.

The reasoning behind this hypothesis is the idea that the more active a person is, the greater the opportunities s/he will have to meet other individuals and interact with them. This will lead, we believe, to an increase in the diversity of ties one has. Our second hypothesis is related to time:

H2a. Length of time in the movement will be positively associated with diversity of occupational ties to other environmentalists.

The longer one spends in the movement, the greater the opportunities to meet with others, which will lead to more ties to a diversity of others. Finally, it is possible that both level of activism and diversity of ties are related to length of time in the movement. The longer someone belongs to the movement the more opportunities they have to increase their (aggregate) level of activism. In addition, the longer someone belongs to the movement the more opportunities they have to develop ties. Hence, we need to control for time in our analyses. We control for time in our third hypothesis:

H3a. Level of activism will be positively associated with diversity of occupational ties to other environmentalists, net of length of time in the movement.

In short, our first set of hypotheses allows us to examine whether or not the production of network social capital is a function of level of activism. The greater the degree of activism, the more social capital one generates through increasingly diverse network ties. It may be suggested, however, that this logic is reversed: namely, that rather than network ties being formed after joining the movement people with larger more diverse networks are simply more likely to be drawn into the movement in the first place. Indeed, the key role that network ties play in bringing people into a social movement and activism is by now well understood (see McAdam, 2003 for a review). Here we develop a second set of hypotheses that allows us to control for this possibility. In general we maintain that while it is possible that movement members may know a number of people prior to joining the movement, it is likely that they develop most of their ties to other environmental movement organization members after and as a result of participation in environmental movement activities.

To examine this we formulate three hypotheses that are identical to the previous hypotheses with the addition of the control variable "diversity of occupational ties in general"; e.g., to others regardless of their Environmental Social Movement Organization (ESMO hereafter) membership status. This allows us to examine the relationship between level of activism and diversity of ties to those within their movement organization, controlling for the diversity of occupational ties they have in general. First, we expect that

H1b. Level of activism will be positively associated with diversity of occupational ties to other environmentalists, net of diversity of occupational ties in general.

Second, we expect that 
H2b. Length of time in the movement will be positively associated with diversity of occupational ties to other environmentalists, net of diversity of occupational ties in general.

Finally, we control for both length of time in the movement and diversity of occupational ties in general in order to focus on the net association between level of activism and diversity of ties to other environmentalists; we expect that

H3b. Level of activism will be positively associated with diversity of occupational ties to other environmentalists, net of length of time in the movement, and net of diversity of occupational ties in general.

Taking diversity of occupational ties to other environmentalists as our major indicator of social capital through networks, we expect to find that regardless of the length of time one is a member of an ESMO, or the diversity of occupational ties one has in general, one's level of activism will be a significant predictor of the diversity of social ties one has to ESMO members. Greater activism, we predict, leads to greater diversity of social ties to other environmentalists and thereby is a net positive social outcome benefit. If our hypotheses are supported, the production of social capital as embedded in networks will need to be included as yet a fourth possible benefit - a "social benefit" - of social movement activity.

\section{Data and measures}

Several Supplementary tables, available on the web, provide details on the measurement of variables, the original questionnaire item for collecting the tie data, as well as results from several supplementary analyses. Data for the following analysis comes from a study of the British Columbia Wilderness Preservation movement (on the movement, see Tindall and Begoray, 1993; Wilson, 1998; Shaw, 2002; Tindall, 2002; Tindall and Cormier, 2008). A self-administered mail questionnaire was distributed to members of three formal Environmental Social Movement Organizations (ESMOs) living in greater Victoria, the capital of British Columbia, Canada. These respondents were drawn from organizations that are component parts of the Wilderness Preservation movement: the Sierra Club of Western Canada (SCWC), the Western Canada Wilderness Committee (WCWC), and the Carmanah Forestry Society (CFS).

For two of the groups a systematic random sampling procedure was employed. For a third, which is a smaller organization, a census of members was conducted. The response rates for the three groups were: Group A 35\% $(N=146)$, Group B 35\% $(N=64)$, Group C $11 \%$ $(N=187)$. The response rates for the surveys were relatively low in absolute terms, though not necessarily in comparative terms (see Muller and Opp, 1986; Opp, 1986).

The current sample varies from the general public in several regards. Members of our sample tend to have higher levels of formal education, to have higher levels of income, and to be more likely to be from upper-middle-class and middle-class white-collar occupations. In terms of the age and gender distribution, the sample reflects the general population quite closely. Because the characteristics of the sample generally reflect the characteristics of the population who participate in new social movements (e.g., those with higher levels of income and education, and those from middleand upper-class locations are more likely to participate), we do not feel that these differences from the general public present a substantial problem for the research questions being examined here. It should also be noted that the distribution of scores for level of activism among the respondents is approximately normally distributed. Thus some people have low levels of activism, some have high levels of activism, but the average respondent is moderately active.
To further assess the possibility of sampling bias related to non-response (regarding issues related to non-response see Moore and Tarnai, 2002; Groves, 2006) we conducted an analysis of late responders. This analysis revealed no obvious sampling biases. $^{1}$

In sum, while the response rate is somewhat low, it is comparable to similar studies. Further, as we are testing theoretical correlations rather than trying to establish precise parameter estimates and there is substantial variation for the key variables, some sampling bias should not present a substantial problem (see Opp, 1986). Finally, there is no evidence of substantial sampling bias.

\subsection{The position generator}

Nan Lin's (2001a,b) definition of social capital provides the conceptual backdrop for the operationalization and measurement of the independent variable (i.e., diversity of social ties) used in this analysis. For Lin, social capital consists of "resources embedded in a social structure that are accessed and/or mobilized in purposive actions" (Lin et al., 2001b:58). Unhappy with the popular "name-generator" strategy (c.f., Laumann, 1973; Wellman, 1979) to measure access to social capital, Lin and Dumin (1986) developed the "position-generator" method (Lin et al., 2001b; Lin and Erickson, 2008). The technique requires respondents to indicate contact (e.g., with a family member, a friend, an acquaintance, etc.), if any, with a sample of ordered hierarchical, usually occupationbased positions (e.g., lawyer, high school teacher, carpenter, etc.). The major strength of this technique over the name-generator strategy is that it better reflects access individuals have to structurally embedded resources (Lin et al., 2001b; Lin and Erickson, 2008). ${ }^{2}$

The position-generator has already demonstrated its usefulness in measuring social capital outcomes in a variety of settings. Erickson (1996), for instance, has used it in combination with Wright's (1985) class rankings to study the relationship between class and culture in the private security industry in Toronto, Canada. Research into how people use cultural and/or social capital in instrumental ways for social mobility, status and prestige, in fact, has to date been the most common use of the position generator. The research question that is commonly asked is: how is differential access to social capital associated with differential outcomes in terms of job prestige, income, status, and social class (Lin and Dumin, 1986; Lin, 2001a; Lin et al., 2001b; Lin and Erickson, 2008). This work with the position-generator has effectively demonstrated the importance of accessing social and cultural capital for the purpose of social mobility.

Until recently the position-generator has been used almost exclusively for social mobility studies (for some exceptions, see Côté and Erickson, 2009; Bekkers et al., 2008; Miyata et al., 2008; Hsung and Lin, 2008; Enns et al., 2008; Tindall and Cormier, 2008; Magee, 2008). Here we apply it to the production of social capital within the field of social movements and collective action.

\footnotetext{
1 Contact the first author for more information.

2 These responses allow for the construction of at least three measures of access to social network capital (Lin et al., 2001b:63). The range of accessibility to occupations (e.g., the distance between the highest (e.g., doctor) and the lowest (e.g., truck driver), the upper reachability (e.g., the prestige of the highest position accessed), or the extensity to different occupations (e.g., the number of positions accessed). Our measure comes closest to this last measure, although we use the terms "range of ties" (Burt, 1980) and "diversity of ties" interchangeably to capture Lin et al.'s (2001b) notion of extensity. Burt (1980) used the term "range" slightly differently from Lin. In Burt's usage range refers to the number of different social locations (or groups) that one is tied to. This is consistent with what we mean by "range" or "diversity of ties".
} 


\subsection{Dependent variable: diversity of ties to ESMO members}

The position generator instrument used in this study was adapted from Erickson (see Erickson, 1996; for a related study using an expanded version of this measure see Erickson, 2004). Erickson's original instrument utilized the format of Lin and Dumin (1986), but was more structurally oriented in terms of focussing on a variety of class locations, and thus drew upon the work of Wright in identifying categories and occupations (Wright, 1985).

Erickson (1996) included a category for control of property (business owners outside your company) and two for control of organizations (business owners who run an establishment other than your own company, and supervisor). Erickson's original instrument also included a number of professions and semiprofessions, several blue collar trades, and several police ranks (as her study focussed specifically on the security industry). Erickson's instrument included a total of 21 occupational categories (including three for different types of police officers that were later collapsed into a single category) that varies in terms of these class locations.

The current work borrows from, and elaborates upon Erickson's version of the position generator. The present version of the measure include a greater number of categories (40 in total), and also provides a minor focus on ties to those employed in natural resource occupations (such as loggers, mill workers, fishermen/fisherwomen), and ties to politicians (as the current study focussed on social movement mobilization regarding environmental issues related to forestry). The occupations in the current instrument ranged from higher prestige (such as business managers, doctors, university professors) to mid-level (nurses, social workers, primary school or secondary school teachers), to lower status (truck drivers, waiters/waitresses, loggers) (for information on the measurement of occupational prestige and socio-economic status in Canada see Blishen et al., 1987; Boyd, 2008; also, for an internationally comparable scale see Ganzeboom and Treiman, 1996).

Respondents were asked whether they knew of any acquaintances, close friends, or relatives in a series of 40 occupations, and then for each occupation they were asked if they knew someone in the occupation who was a member of their ESMO (environmental social movement organization). Responses were coded at the binary level for each occupation: the respondent knew someone in that occupation who belonged to the $\mathrm{ESMO}=1$; the respondent did not know anyone in that occupation who belonged to the $\mathrm{ESMO}=0$. The responses to the individual occupational items were then summed to create an index. The higher the value for the index, the greater the network range or network diversity. The survey item is provided in Supplementary Table 2 in its entirety. (See Tindall and Cormier, 2008 for more details.) Percentages for this item are provided in Supplementary Table 3.

\subsection{Key independent variables}

Supplementary Table 1 lists and provides brief descriptions of all of the variables used in the analysis, and Table A.1 provides descriptive statistics for each variable. The control variables are socio-demographic in nature. Our three independent variables of central interest - level of activism, length of time and diversity of general ties - need greater explanation, and thus will be described below. We will also add some commentary about our class measures.

\subsection{Level of activism}

Our main independent variable, level of activism, is an aggregate measure combining seventeen types of participation in the environmental movement (Tindall, 2002). One either participated (coded as 1 ) or did not participate (coded as 0 ) in the following activities: (1) donate money to a wilderness preservation or other environmental organization; (2) write a letter to a government official regarding a wilderness preservation issue; (3) write a letter to a newspaper regarding wilderness preservation (or forestry related issues); (4) write a letter to a logging company about a forestry (or wilderness) issue; (5) write a letter to another organization regarding a wilderness preservation issue; (6) sign a petition to preserve a wilderness area; (7) participate in trail building; (8) attend a community meeting about wilderness preservation and/or forestry; (9) attend a rally or protest demonstration on the lawns of the legislature to support wilderness preservation; (10) participate in an information campaign for the general public about wilderness preservation; (11) advertise in the media to promote wilderness preservation; (12) make a presentation to a public body about wilderness preservation and/or forestry related issues; (13) give a lecture on wilderness preservation and/or logging practices to a school group or voluntary organization; (14) participate in a press release/conference (regarding wilderness preservation and forestry-related issues); (15) serve as a representative on an advisory board formed around wilderness preservation or forestry related issues; (16) purchase a book, t-shirt, poster, mug or other merchandise from an environmental organization; and (17) other activities.

It is assumed that the greater the number of activities a movement member has participated in, the more active she or he is. Factor and reliability analysis strongly supported the creation of a general index measure of activism based on these seventeen items (see Tindall, 2002).

\subsection{Length of membership}

The variable "length of membership" is the length of time (in years) since the respondent had joined the environmental social movement organization.

\subsection{Diversity of occupational ties in general}

The variable "diversity of occupational ties in general" is based on the following procedures. Respondents were asked whether they knew of any acquaintances, close friends, or relatives in a series of 40 occupations. If a person knew someone in an occupation they received a score of 1 . If they did not know anyone in that occupation they received a score of 0 . The responses to the individual occupational items were then summed to create an index. Thus, this is a measure of diversity of occupational ties in general (regardless of the alters' ESMO membership status).

\subsection{Class measures}

As occupational status/class has been central to the literature that has utilized the position generator, we will say a few words about class and occupational status here. We have included this material in the methods rather than in the literature section as it is less germane to our theoretical arguments, but is relevant to our selection of "control variables".

A set of arguments loosely drawn together under the rubric of new social movement theory has been developed to explain the rise to prominence of contemporary social movements over the past several decades. Those who have examined the composition of contemporary movements have put forth the claim that new social movements (NSMs) are comprised of members of the "new middle class" (or at least parts of the new middle class). Some writers equate the "new class" with a conglomeration of occupations described as "social and cultural specialists" (e.g., professors, writers, and artists; see Brint, 1984; Kriesi, 1989). 
Table 1

Multiple regression models explaining network social capital (diversity of occupational ties to other environmentalists). ${ }^{\text {a }}$

\begin{tabular}{|c|c|c|c|c|c|c|c|c|c|}
\hline \multirow[t]{2}{*}{$\begin{array}{l}\text { Socio-economic and demographic } \\
\text { control variables }\end{array}$} & \multirow[t]{2}{*}{ Model 1} & \multirow[t]{2}{*}{ Model 2} & \multirow[t]{2}{*}{ Model 3} & \multicolumn{2}{|c|}{$\begin{array}{l}\text { Model } 3 \\
\text { (unstandardized) }\end{array}$} & \multirow[t]{2}{*}{ Model 4} & \multirow[t]{2}{*}{ Model 5} & \multicolumn{2}{|c|}{$\begin{array}{l}\text { Model } 5 \\
\text { (unstandardized) }\end{array}$} \\
\hline & & & & Unst. coeff & Std error & & & Unst. coeff. & Std. error \\
\hline Education & .084 & .088 & .048 & .044 & .055 & .072 & .035 & .032 & .055 \\
\hline Gender $($ male $=1)$ & .021 & .023 & .000 & -.001 & .224 & .023 & .001 & .003 & .221 \\
\hline Age & -.094 & $-.175^{*}$ & -.042 & -.005 & .010 & -.152 & -.026 & -.003 & .010 \\
\hline Full Employment (employed ft=1) & -.058 & -.048 & -.013 & -.050 & .260 & -.075 & -.037 & -.147 & .258 \\
\hline Retired (retired $=1$ ) & -.157 & -.100 & -.120 & -.638 & .448 & -.082 & -.104 & -.552 & .443 \\
\hline Business Owners & -.039 & -.009 & -.019 & -.140 & .435 & -.018 & -.027 & -.198 & .429 \\
\hline Managers & .072 & .090 & .071 & -.555 & .456 & .091 & .072 & .563 & .449 \\
\hline New middle class & -.033 & -.008 & -.051 & -.209 & .294 & -.008 & -.050 & -.203 & .290 \\
\hline Personal income (log) & -.003 & -.006 & -.031 & -.058 & .114 & -.012 & -.035 & -.066 & .112 \\
\hline Time: length of membership & - & $.195^{* * * *}$ & .056 & -.027 & .028 & $.195^{* * * *}$ & .060 & .028 & .028 \\
\hline Mobilization: level of individual activism & - & - & $.404^{* * * *}$ & $.240^{* * * *}$ & .034 & - & $.392^{* * * *}$ & $.233^{* * * *}$ & .034 \\
\hline Total diversity of ties to occupations & - & - & - & - & - & $.191^{* * * *}$ & $.165^{* * * *}$ & $.038^{* * *}$ & .013 \\
\hline Constant & & & & & & & & -.683 & .859 \\
\hline$R^{2}$ & .056 & $.090^{* * *}$ & $.226^{* * * *}$ & $.226^{* * * *}$ & & $.123^{* * * *}$ & $.251^{* * * *}$ & $.251^{* * * *}$ & \\
\hline Adjusted $R^{2}$ & .026 & $.058^{* * *}$ & $.196^{* * * *}$ & $.196^{* * * *}$ & & $.089^{* * * *}$ & $.219^{* * * *}$ & $.219^{* * * * *}$ & \\
\hline$N$ & 294 & 294 & 294 & 294 & & 294 & 294 & 294 & \\
\hline
\end{tabular}

a Standardized coefficients are presented except where stated.

${ }^{*} p \leq .05$.

${ }^{* *} p \leq .01$.

${ }^{* * * *} p \leq .005$.

**** $p \leq .001$.

This social movement literature dovestails with some of the work on social networks and social capital, and in particular, with research using the position generator. Lin (1999) has provided the "strength of position proposition": social resources are affected by the original position of ego (as represented by parental resources or previous resources). And various studies have found that network diversity is, indeed, associated with class, occupational status, and/or income (Erickson, 1996; Van der Gaag et al., 2008; Moren Cross and Lin, 2008). For example, in a recent representative survey of the British population, Li et al. found that people with higher occupational status, as well as those who were upwardly mobile, had ties to a greater diversity of occupations ( $\mathrm{Li}$ et al., 2008).

Thus new social movement theorists argue that the new middle class in general, and social and cultural specialists in particular, will be more involved in new social movements. Extrapolating from this and synthesizing these insights with the social capital literature we would expect the new middle class to have greater network diversity (in terms of their ties to people from different occupations within the movement). Similarly, social capital theorists predict that those with higher occupational status and/or those from higher class positions, will have greater network diversity.

As occupational status is a major component of theoretical models that link the position generator to social capital, we have given some emphasis to this literature. Nevertheless, in the present study, occupation/class is treated as a "control" variable rather than a central explanatory variable as our focus is upon the effects of activism. Our classification of occupation/class was informed partly by Brint (1984), and partly by Wright (1985). For the sake of parsimony we have collapsed several new middle class categories into a single aggregate category which we use in the present analyses. We have also done additional analyses that are not reported here with the more fine grained categories (social and cultural specialists in particular) but these results were undistinguishable from the present results, and thus we present the simplified categorization scheme here.

Based on the two sets of literatures noted above, the implicit hypothesis is that Business Owners, Managers, and occupants of New Middle Class positions will have greater network diversity than occupants of lower class positions in the reference categories.

\section{Results}

Table 1 provides a series of multiples regression models that we use to test the hypotheses. The dependent variable for these analyses is diversity of occupational ties to other environmentalists (TOE). (We will use the abbreviation TOE for "to other environmentalists" hereafter.)

Model 1 of Table 1 provides a model for education, gender, age, employment status, retirement status, several dummy variables for class location (business owners, managers, new middle class), and personal income (log). The variables included in this model were selected for "control" purposes. None of these control variables has a significant effect.

In model 2 we add our first variable of substantial theoretical interest, length of membership with the ESMO. Here we find a positive and significant association between length of membership and diversity of ties TOE. As expected (and stated in $\mathrm{H} 2 \mathrm{a}$ ) the longer people have belonged to an ESMO, the greater the number of ties they have made to different occupations TOE. Of minor note, age is now significantly negatively associated with diversity of occupational ties TOE. (Younger people had more diverse occupational ties TOE.)

In Model 3 we add the variable of central theoretical interest to this paper, level of activism. As expected (and stated in H1a) the more active individuals are, the greater their diversity of occupational ties TOE. It should also be noted that in this model, when level of activism is added, the coefficient for length of membership declines in magnitude and becomes non-significant. (Age also becomes non-significant.) This suggests that the effect of length of membership is indirect via level of activism. That is, the longer people belong to an ESMO, the greater their opportunities for participating in movement activities, and the more movement activities they participate in, the greater the diversity of ties they make TOE. This also supports H3a.

In Model 4, level of activism is removed from the model, and total diversity of occupational ties is added to the model. (This includes ties to different occupations regardless of whether or not the alter is a member of the ESMO.) Here we find that length of membership is positive and significant, and total diversity of occupation ties is also positive and significant. The fact that the effect for length of membership is significant (and positive) net of diversity of occupational ties in general supports H2b. 
Finally, in model 5, level of activism is reintroduced into the model. Here level of activism is significantly and positively associated with diversity of occupational ties TOE net of length of membership, diversity of occupational ties in general, and net of the control variables. ${ }^{3}$ This supports H3B. ${ }^{4}$ Indeed, level of activism is the strongest predictor of diversity of occupational ties TOE. It should also be noted that length of membership again becomes non-significant when level of activism is included in the model (as in model 3), but total diversity of occupational ties is positively and significantly associated with diversity of occupational ties TOE. ${ }^{5}$ In models 1,2 and 4 only standardized coefficients are provided. In the "full models" 3 , and 5 both standardized and unstandardized coefficients are provided. ${ }^{6}$

In sum, all of our hypotheses are supported by the findings. The result of key theoretical significance is that those who are more active in the environmental movement develop a greater diversity of ties TOE. This appears to happen over time (in results not shown here, level of activism is positively and significantly associated with length of membership; $r=.27, p<.001$ ).

\section{Discussion}

The evidence that social movements matter is building. The primary goal of this analysis has been to contribute to this evidence while at the same time expanding the ways in which social movement outcomes are studied and analyzed. Along with the political, biographical and cultural benefits of collective action, we encourage greater emphasis on what we think are the social benefits of social movement participation. Our study of the British Columbia Wilderness Preservation movement has demonstrated how an individual's "network social capital" is increased through activism in a social movement. The more active a person is in a movement - for instance, by attending rallies and other movement events - the more diverse the occupational ties one develops with others within those movement contexts.

This study has provided substantial evidence of an empirical correlation between the level of activism of individuals, and the diversity of occupational ties that people have to movement participants. Our theoretical claim is that the more active one is, the greater the diversity of alters one meets, and thus the more occupationally diverse one's network is (at least regarding ties to other movement participants).

One weakness of the present analysis is that we cannot be sure whether the production of diverse occupational ties occurs before or after activism. That is, is the observed effect a "social influence effect", or a "social selection effect" (Snijders et al., 2010).

In our analysis, we provide a model (Table 1, Model 5) where diversity of ties in general is controlled for. This provides some evidence that the correlation between activism and diversity of

3 Two cases with substantial outliers have been removed from the analyses for these models. There is no substantive difference and/or difference in which variables are significant between models that include the outliers, and those which do not. However, including the outliers inflates the magnitude of several of the key regression coefficients somewhat. Thus by excluding the outliers we offer more conservative results.

${ }^{4}$ This also implicitly supports H1B. A separate regression was also run, and the results provide support for $\mathrm{H} 1 \mathrm{~B}$ but are not shown here due to space considerations.

${ }^{5}$ As one of the reviewers has noted, because of the way the variables are measured some of the effect for diversity of ties in general may be due to autocorrelation. However, we would maintain that as this is a control variable in the present analysis, it does not affect our theoretical claim. This will become further evident in the discussion when we describe a supplementary analysis.

${ }^{6}$ We have tested for the possibility of a curvilinear effect for age in results not shown here. As there was no curvilinear effect in the final model, we only present the effect for the linear effect - which is also non-significant in the full models. occupational ties to alters in the movement is not simply a function of diversity of occupational ties in general. Never the less, some questions remain about the causal direction underlying the main effect of interest in this study.

To remedy this, we have conducted a supplementary analysis of another data set that we collected. This supplementary data set was obtained from a nation-wide probability sample of environmental organization members in Canada. The measures were similar to those reported earlier in this paper, with one key difference. In this supplementary study we asked about the diversity of occupational ties to people who were "met as a result of environmental movement activities". The analysis from this supplementary study reveals a strong net positive effect for diversity of occupational ties to people who were met as a result of environmental movement activities. The standardized regression coefficient is $b=.56, p<.001$ controlling for socio-economic-demographic variables, and length of environmental organization membership. After these other variables have been controlled, adding level of individual activism to the model explains an additional $28 \%$ of the variation in diversity of occupational ties to people met through the movement (the results of this regression are available in Supplementary Table 4. More details on this study can be obtained from Tindall et al. (2010), and by contacting the first author). In our view, this provides quite strong evidence that the more active one is, the greater the diversity of occupational ties one makes to others through movement activities. This effect is not tautological. Nor is it trivial. As social capital scholars have pointed out, having diverse ties can have beneficial consequences for individuals (Erickson, 2003).

We have noted that the "traditional approach" to study networks and activism has been to treat network ties as the independent variable, and activism as the dependent variable. In this paper, we have turned this relationship around, to look at activism as the independent variable, and network ties as the dependent variable. This is because we believe we have identified an empirical phenomenon - the production of network social capital as a result of activism - that has not been previously studied by social movement scholars.

Nevertheless, we believe that it is almost certainly the case that reciprocal influence is at work through these processes. We have evidence from the supplementary analysis (see Supplementary Table 5) that activism is positively associated with diversity of occupational ties in general. It is likely in most cases that some ties pre-exist an individual's participation in a movement, and further ties are made as a result of his or her activism. In the supplementary analysis we have evidence that activism does lead to an increase in the diversity of certain occupational ties. What we don't know is what proportion of these newly formed ties are inside versus outside of the movement. Diani (1997) emphasizes that ties to those outside of the movement that are created as a result of social movement mobilization theoretically constitute a particular type of social movement capital that arises as a result of mobilization. Further research on this topic should look at the distinction between ties within and outside of the movement.

What is the net social benefit produced by social movement participation? In this case, we argue that one benefit is social capital. Previous work on the benefits of social capital has, with a few exceptions, focused on how resources accessed through social network ties have enabled individuals to benefit in terms of social mobility; it has helped people obtain financial power, prestige and status (see Lin et al., 2001a). According to Lin (2001b), individuals use social capital resources in instrumental and purposive ways. The resources they access through ties and connections to the broader social structure (i.e., measured by their ties to the occupational structure), help them to find a job and get promoted. 
These individual social capital benefits can be translated into the language of collective action. By being active in a movement or a movement organization, individuals increase their social capital resources. This results in four individual social benefits. First, individual members become more informed about issues that interest them. Second, gaining social capital resources through contacts with politicians means that an individual's influence and impact in the political sphere increases. Third, the "social certification" that comes from contacts with influential and powerful others means that activists can, if they wish, speak legitimately on behalf of the movement. A fourth social capital benefit is the sense of identity, recognition and solidarity that develops as a result of interacting with a diverse group of others within the context of social movement activity.

This last point about social capital and solidarity points to an important division of labor that has developed within the literature on social capital outcomes. Lin $(1999,2001 b)$ maintains that social capital is best studied as a resource accessed and used by individuals (for other examples see, Burt, 1992, 1997; Marsden and Hurlbert, 1988; Portes, 1998; Portes and Sensenbrenner, 1993). This analytical strategy focuses on how individuals invest in social relations and extract social capital benefits from these social relations usually for purposes of greater social mobility (Lin, 2001b:8). However a second analytical strategy has been to pull back from the individual level of analysis and examine the larger community and society-based benefits that result from the production of social capital. While Bourdieu (1986) and Coleman (1988) have discussed social capital at this broader community level, Putnam's (1993, $1995,2000)$ work exemplifies this trend. The general argument is that the development of dense social ties within a community leads to increased networks of trust (Tilly, 2005) and solidarity between members of that community. From this perspective the production of social capital is not necessarily an individual benefit - although individuals might benefit by the mere fact of living in such a community or society - but rather it is a net collective benefit.

This study of the consequences of movement activism has taken us a step further towards greater elucidation of the social benefit outcomes of movement activity. Movements have effects beyond the intended political and policy goals stated by the movement's leaders. Individuals, organizations and whole communities can also benefit from the increased participation of people in social movement activity.

\section{Appendix A.}

Table A.1

Descriptive statistics.

\begin{tabular}{|c|c|c|c|c|c|c|}
\hline Variable & Minimum & Maximum & Mean & S.D. & $\%$ & $N$ \\
\hline Education & 7.00 & 18.00 & 15.64 & 2.14 & & 294 \\
\hline Gender $($ male $=1)$ & & & & & 48.6 & 294 \\
\hline Age & 15.00 & 88.00 & 45.80 & 15.90 & & 294 \\
\hline Full employment & & & & & 54.2 & 294 \\
\hline Retired & & & & & 16.7 & 294 \\
\hline Managers & & & & & 6.8 & 294 \\
\hline Business owners & & & & & 8.2 & 294 \\
\hline New middle class & & & & & 38.4 & 294 \\
\hline Personal income (log) & -2.00 & 5.13 & 4.30 & 1.05 & & 294 \\
\hline $\begin{array}{l}\text { Length of } \\
\text { membership }\end{array}$ & 0.17 & 40.00 & 3.82 & 4.16 & & 294 \\
\hline Level of activism & 0.00 & 17.00 & 5.00 & 3.33 & & 294 \\
\hline $\begin{array}{l}\text { Total diversity of } \\
\text { occupational ties }\end{array}$ & 0.00 & 40.00 & 17.30 & 8.62 & & 294 \\
\hline $\begin{array}{l}\text { Diversity of } \\
\text { occupational ties to } \\
\text { ESMO members }\end{array}$ & 0.00 & 10.00 & 1.10 & 1.98 & & 294 \\
\hline
\end{tabular}

\section{Appendix B. Supplementary data}

Supplementary data associated with this article can be found, in the online version, at doi:10.1016/j.socnet.2011.12.007.

\section{References}

Amenta, E., Carruthers, B., Zylan, Y., 1992. A hero for the aged? The Townsend Movement, the Political Mediation Model, and U.S. Old-Age Policy, 1934-1950. The American Journal of Sociology 98, 308-339.

Andrews, K.T., 1997. The impacts of social movements on the political process: The Civil Rights Movement And Black Electoral Politics in Mississippi. American Sociological Review 62, 800-819.

Andrews, K.T., 2004. Freedom Is a Constant Struggle. University of Chicago Press, Chicago.

Bekkers, R., Völker, B., van der Gaag, M., Flap, H., 2008. Social Networks of Participation in Voluntary Associations. In: Lin, N., Erickson, B. (Eds.), Social Capital: An International Research Program. Oxford University Press, Oxford, UK, pp. 185-205.

Blishen, B.R., Carroll, W.K., Moore, C., 1987. The 1981 Socioeconomic Index for Occupations in Canada. Canadian Review of Sociology and Anthropology 24 (4), $465-488$.

Bourdieu, P., 1986. The Forms of Capital. In: Richardson, J.G. (Ed.), Handbook of Theory and Research for the Sociology of Education. Greenwood Press, Westport, pp. 241-258.

Boyd, M., 2008. A Socioeconomic Scale for Canada: Measuring Occupational Status from the Census. Canadian Review of Sociology 45 (1), 51-91.

Brint, S., 1984. 'New-class' and cumulative trend explanations of the liberal political attitudes of professionals. American Journal of Sociology 90, 30-71.

Burstein, P., 1999. Social Movements and Public Policy. In: Giugni, M.G., McAdam, D., Tilly, C. (Eds.), How Social Movements Matter. University of Minnesota Press, Minneapolis, pp. 3-21.

Burt, R., 1980. Models of network structure. Annual Review of Sociology 6, 79-141.

Burt, R.S., 1992. Structural Holes: The Social Structure of Competition. Harvard University Press, Cambridge, MA.

Burt, R.S., 1997. The contingent value of social capital. Administrative Science Quarterly $42,339-365$.

Coleman, J.S., 1988. Social capital in the creation of human capital. American Journa of Sociology 94, 95-120.

Côté, R.R., Erickson, B.H., 2009. Untangling the roots of tolerance: how forms of social capital shape attitudes toward ethnic minorities and immigrants. American Behavioral Scientist 52 (12), 1664-1689.

Diani, M., 1995. Green Networks: A Structural Analysis of the Italian Environmental Movement. Edinburgh University Press.

Diani, M., 1997. Social movements and social capital: a network perspective on movement outcomes. Mobilization: An International Journal 2, 129-147.

Diani, M., 2003. Leaders' or 'brokers'? Positions and influence in social movement networks. In: Diani, M., McAdam, D. (Eds.), Social Movements and Networks: Relational Approaches to Collective Action. University of Oxford Press, Oxford, pp. 105-122.

Diani, M., 2009. The structural bases of protest events, multiple memberships and networks in the February 15th 2003 anti-war demonstrations. Acta Sociologica 52, 63-83.

Diani, M., McAdam, D. (Eds.), 2003. Social Movements and Networks: Relational Approaches to Collective Action. Oxford University Press, Oxford.

Enns, S., Malinick, T., Matthews, R., 2008. It's not only who you know, it's also where they are: using the position generator to investigate the structure of access to embedded resources. In: Lin, N., Erickson, B. (Eds.), Social Capital: An International Research Program. Oxford University Press, Oxford, UK, pp. 255-281.

Erickson, B., 1996. Culture, class and connections. American Journal of Sociology 102, 217-251.

Erickson, B., 2003. Social networks: the value of variety. Contexts 2 (1), 25-31.

Erickson, B., 2004. The distribution of gendered social capital in Canada. In: Flap, B., Volker (Eds.), Creation and Returns of Social Capital: A New Research Program. Routledge, London/New York, pp. 27-50.

Feld, S.L., 1981. The focused organization of social ties. American Journal of Sociology $86(5), 1015-1035$.

Ganzeboom, H.B., Treiman, D.J., 1996. Internationally comparable measures of occupational status for the 1988 International Standard Classification of Occupations. Social Science Research 25, 201-239.

Giugni, M.G., 1999. How social movements matter: past research, present problems, future developments. In: Giugni, M.G., McAdam, D., Tilly, C. (Eds.), How Social Movements Matter. University of Minnesota Press, Minneapolis, pp. xiii-xxxiii.

Giugni, M.G., McAdam, D., Tilly, C. (Eds.), 1999. How Social Movements Matter. University of Minnesota Press, Minneapolis.

Gould, R.V., 1993. Collective action and network structure. American Sociological Review 58, 82-196.

Groves, R.M., 2006. Nonresponse rates and nonresponse bias in household surveys Public Opinion Quarterly 70 (5), 646-675.

Harshaw, H.W., Tindall, D.B., 2005. Social structure, identities, and values: a network approach to understanding people's relationships to forests. Journal of Leisure Research 37 (4), 426-449.

Hsung, R.-M., Lin, Y.-J., 2008. Social capital of personnel managers: causes and return of position-generated networks and participation in voluntary associations. In: 
Lin, N., Erickson, B. (Eds.), Social Capital: An International Research Program. Oxford University Press, Oxford, UK, pp. 234-254.

Kitts, J.A., 1999. Not in our backyard: solidarity, social networks, and the ecology of environmental mobilization. Sociological Inquiry 69 (4), 551-574.

Kriesi, H., 1989. New social movements and the new class in the Netherlands. American Journal of Sociology 94, 1078-1116.

Laumann, E., 1973. Bonds of Pluralism: The Forms and Substance of Urban Social Networks. Wiley, New York.

Li, Y., Savage, M., Warde, A., 2008. Social mobility and social capital in contemporary Britain. British Journal of Sociology 59 (3), 391-411.

Lin, N., 1999. Social networks and status attainment. Annual Review of Sociology 25 , 467-487.

Lin, N., 2001a. Social Capital: A Theory of Social Structure and Action. University of Cambridge Press, New York.

Lin, N., 2001b. Building a network theory of social capital. In: Lin, N., Cook, K., Burt, R. (Eds.), Social Capital: Theory and Research. Aldine De Gruyter, New York, pp. 3-29.

Lin, N., Cook, K., Burt, R., 2001a. Social Capital: Theory and Research. Aldine De Gruyter, New York.

Lin, N., Dumin, M., 1986. Access to occupations through social ties. Social Networks $8,365-385$.

Lin, N., Erickson, B. (Eds.), 2008. Social Capital: An International Research Program. Oxford University Press, Oxford, UK.

Lin, N., Fu, Y., Hsung, R., 2001b. Position generator: measurement techniques for investigations of social capital. In: Lin, N., Cook, K., Burt, R. (Eds.), Social Capital: Theory and Research. Aldine De Gruyter, New York, NY, pp. 57-81.

Magee, M.P., 2008. Civic participation and social capital: a social network analysis in two American Counties. In: Lin, N., Erickson, B. (Eds.), Social Capital: An International Research Program. Oxford University Press, Oxford, UK, pp. 308-327.

Marsden, P., Hurlbert, J., 1988. Social resources and mobility outcomes: a replication and extension. Social Forces 52, 122-131.

McAdam, D., 1986. Recruitment to high-risk activism: the case of freedom summer. American Journal of Sociology 92, 64-90.

McAdam, D., 1988. Freedom Summer. Oxford University Press, New York.

McAdam, D., 1989. The biographical consequences of activity. American Sociological Review 54, 744-760.

McAdam, D., 1999. The Biographical Impact of Activism. In: Giugni, M.G., McAdam, D., Tilly, C. (Eds.), How Social Movements Matter. University of Minnesota Press, Minneapolis, pp. 117-146.

McAdam, D., 2003. Beyond structural analysis: toward a more dynamic understanding of social movements. In: Diani, M., McAdam, D. (Eds.), Social Movements and Networks: Relational Approaches to Collective Action. Oxford University Press, Oxford, pp. 281-298.

McCammon, K.C., Granberg, E., Mowery, C., 2001. How movements win: gendered opportunity structures and U.S. Women's Suffrage Movements, 1866 to 1919. American Sociological Review 66, 49-70.

Meyer, D.S., 1999. How the Cold War Was Really Won: The Effects of the Antinuclear Movements of the 1980. In: Giugni, M.G., McAdam, D., Tilly, C. (Eds.), How Social Movements Matter. University of Minnesota Press, Minneapolis, pp. 182-203.

Miyata, K., Ikeda, K., Kobayshi, T., 2008. The Internet, Social Capital, Civic Engagement, and Gender in Japan. In: Lin, N., Erickson, B. (Eds.), Social Capital: An International Research Program. Oxford University Press, Oxford, UK, pp. 206-233.

Moren Cross, J.L., Lin, N., 2008. Access to Social Capital and Status Attainment in the United States: Racial/Ethnic and Gender Differences. In: Lin, N., Erickson, B. (Eds.), Social Capital: An International Research Program. Oxford University Press, Oxford, UK, pp. 364-379.

Moore, D.L., Tarnai, J., 2002. Evaluating Nonresponse Error in Mail Surveys. In: Groves, R.M., Dillman, D.A., Eltinge, J.L., Little, R.J.A. (Eds.), Survey Nonresponse. John Wiley and Sons Inc., New York, pp. 213-228.
Muller, E.N., Opp, K., 1986. Rational choice and rebellious collective action. American Political Science Review 80, 471-487.

Oliver, P.E., Myers, D.J., 2003. Networks, diffusion, and cycles of collective action In: Diani, M., McAdam, D. (Eds.), Social Movements and Networks: Relational Approaches to Collective Action. University of Oxford Press, Oxford, pp. 173-203.

Opp, K., 1986. Soft Incentives and collective action. Participation in the anti-nuclear movement. British Journal of Political Science 16, 87-112.

Passy, F., 2003. Social movements matter. But How? In: Diani, M., McAdam, D. (Eds.), Social Movements and Networks: Relational Approaches to Collective Action. University of Oxford Press, Oxford, pp. 21-48.

Portes, A., 1998. Social capital: its origins and applications in modern sociology. Annual Review of Sociology 24, 1-24.

Portes, A., Sensenbrenner, J., 1993. Embeddedness and immigration: notes on the social determinants of economic action. American Journal of Sociology 98, $1320-1350$.

Putnam, R.D., 1993. Making Democracy Work: Civic Traditions in Modern Italy. Princeton University Press, Princeton, NJ.

Putnam, R., 1995. Bowling Alone: America's Decline Social Capital. Journal of Democracy $6(1)$.

Putnam, R.D., 2000. Bowling Alone: The Collapse and Revival of American Community. Simon and Schuster, New York.

Rochon, T.R. 1998. Culture Moves: Ideas, Activism and Changing Values. Princeton, NJ.

Shaw, K., 2002. Encountering Clayoquot. In: Magnusson, W., Shaw, K. (Eds.), A Political Space: Reading the Global through Clayoquot Sound. McGill-Queen's University Press, Montreal, pp. 25-66.

Snijders, T.A.B., Van de Bunt, G.G., Steglich, C.E.G., 2010. Introduction to stochastic actor-based models for network dynamics. Social Networks 32, 44-60.

Soule, S., Olzak, S., 2004. When do movements matter? The politics of contingency and the equal rights amendment. American Sociological Review 69, 347-497.

Tilly, C., 2005. Trust and Rule. Cambridge University Press.

Tindall, D.B., 2002. Social networks, identification and participation in an environmental movement: low-medium cost activism within the British Columbia Wilderness Preservation Movement. Canadian Review of Sociology and Anthropology 39 (4), 413-452.

Tindall, D.B., Begoray, N., 1993. Old growth defenders: the battle for the Carmanah Valley. In: Lerner, S. (Ed.), Environmental Stewardship: Studies in Active Earthkeeping. University of Waterloo Geography Series, Waterloo, Ontario, pp. 269-322.

Tindall, D.B., Cormier, J.J., 2008. Gender, network capital, social capital and political capital: the consequences of personal network diversity for environmentalists in British Columbia. In: Lin, N., Erickson, B. (Eds.), Social Capital: An International Research Program. Oxford University Press, Oxford, UK, pp. 282-307.

Tindall, D.B., Robinson, J.L., Diani, M., 2010. The concept of social movement revisited: an empirical investigation. Paper presented at the International Sunbelt Social Network Conference in Riva del Garda, Italy, July 3, 2010.

Tindall, D.B., Stoddart, M.C.J., Diani, M., 2009. The intensity of protest, lifecourse stage, social networks, and the participation of individuals in social movement activism over time. Paper Presented at the International Sunbelt Social Network Conference in San Diego, California, March 15, 2009.

Van der Gaag, M., Snijders, T.A.B., Flap, H., 2008. Position generator measures and the relationship to other social capital measures. In: Lin, N., Erickson, B. (Eds.), Social Capital: An International Research Program. Oxford University Press, Oxford, UK, pp. 27-48.

Wellman, B., 1979. The community question. American Journal of Sociology 84 , 1201-1231.

Wilson, J., 1998. Talk and Log: Wilderness Politics in British Columbia, 1965-96. UBC Press, Vancouver, BC.

Wright, E.O., 1985. Classes. Verso, London. 